\title{
NEUROPSYCHIATRY OF PARKINSON'S DISEASE
}

\author{
Arthur Kummer, Antonio Lucio Teixeira
}

\begin{abstract}
Parkinson's disease (PD) is traditionally regarded as a movement disorder. In recent years, however, non-motor symptoms have been considered significant factors of disability at all stages of the illness. Behavioral and psychological symptoms or neuropsychiatric syndromes associated with PD are frequent and may represent a challenge in the management of these patients. They include anxiety, depression, psychosis, sleep, sexual and impulse control disorders, apathy and cognitive dysfunction. Their pathogenesis in PD is complex, involving neurodegenerative, drug-related and psychological mechanisms. We will review the current knowledge of this growing field, also focusing on the management of theses syndromes.
\end{abstract}

KEY WORDS: Parkinson's disease, neuropsychiatry, psychology, psychiatric disorders.

\begin{abstract}
Neuropsiquiatria da doença de Parkinson
Resumo - A doença de Parkinson (DP) é tradicionalmente conhecida como um distúrbio do movimento. Entretanto, os sintomas não-motores têm sido considerados recentemente como fatores relevantes de incapacidade em todos os estágios da doença. Sintomas motores e comportamentais ou síndromes neuropsiquiátricas associadas à DP são frequentes e seu manejo pode se tornar um verdadeiro desafio. São comuns quadros de ansiedade, depressão, psicose, distúrbios do sono, transtornos do controle do impulso, apatia e disfunções cognitivas. A patogênese desses transtornos na DP é complexa, envolvendo mecanismos degenerativos, psicológicos e relacionados ao tratamento. Neste artigo, revisamos o estado do conhecimento desse campo de interesse crescente, também enfocando o manejo dessas síndromes.
\end{abstract}

PALAVRAS-CHAVE: doença de Parkinson, neuropsiquiatria, psicologia, transtornos psiquiátricos.

Parkinson's disease (PD) is clinically defined by motor signs such as bradikinesia, rigidity, postural instability and rest tremor. Asymmetry of motor signs and a good response to dopaminergic drugs are additional characteristics that support the diagnosis. Although PD diagnosis is based on the motor signs, non-motor aspects of the disease are extremely common and disabling. Since neuroimaging studies are unspecific and reliable biological markers are still lacking, it is essential to know the range of the clinical features of PD for its diagnosis.

Non-motor symptoms of PD are frequent and they can precede the motor signs by several years. These symptoms are challenging in advanced stages of the disease, and they frequently limit the effective treatment of motor signs, leading to increased disability and poor quality of life $\mathrm{e}^{1,2}$. Some PD patients consider their non-motor symptoms even more disabling than motor signs ${ }^{3}$.

The pathophysiology of these disorders is complex.
It is probably multifactorial, involving neurodegenerative process, psychological mechanisms and effects related to pharmacological and non-pharmacological treatment. Despite the high frequency of psychiatric disorders in PD, they are frequently under recognized by physicians.

This article comprehensively reviews the current state of knowledge regarding the main neuropsychiatric syndromes of PD, as well as the available therapies for their treatment.

\section{DEPRESSION}

Depression in PD is the main factor impacting quality of life ${ }^{2,4,5}$. It is associated with an increased mortality rate ${ }^{6}$. Clinically significant depressive symptoms are present in at least $35 \%$ of PD patients ${ }^{7}$. Some authors claimed that depression in PD would be mild to moderate, seldom fulfilling diagnostic criteria for a major depressive disorder. However, the frequency of major depression, minor de-

Neuropsychiatric Branch, Neurology Unit, University Hospital and Neurology Group, Department of Internal Medicine, School of Medicine, Federal University of Minas Gerais (UFMG), Belo Horizonte MG, Brazil.

Received 30 March 2009, received in final form 13 July 2009. Accepted 3 August 2009.

Dr. Arthur Kummer - Departamento de Clínica Médica, Faculdade de Medicina / UFMG - Av. Alfredo Balena 190 - 30130-100 Belo Horizonte MG - Brasil. E-mail:r2kummer@hotmail.com 
pression and dysthymia is now estimated to be $17 \%, 22 \%$ e $13 \%$, respectively ${ }^{7}$. The frequency of depression is lower in the community than in specialized health care centers. Potential risk factors for depression in PD include: female gender, advanced age, cognitive impairment, comorbidity with anxiety, increased severity of the disease, rigid-akinetic variant of PD, postural instability, motor signs nonresponsible to levodopa, and familial history of PD. Patients with comorbid depression have worse motor performance and cognitive functioning when compared to non-depressed patients ${ }^{8}$. The frequency of death and suicidal ideation in these patients are particularly high, although suicide plans and attempts are fortunately rare. The majority of PD patients $(75 \%)$ which present motor fluctuations also have prominent mood swings ${ }^{9}$.

In spite of the high frequency and significant burden of depression in DP, this disorder is seldom diagnosed and of ten undertreated. According to The Global Parkinson's Disease Survey Steering Committee, only $1 \%$ of the patients report depressive symptoms to their physician ${ }^{10}$. An additional problem regarding depression in PD is the fact that the somatic symptoms following depression may superimpose symptoms from PD itself and other comorbidities. Psychomotor slowness, decreased initiative, and blunted affect are depressive symptoms which may be confounded with bradikynesia, stooped posture and hypomimia in PD. Lack of energy, insomnia and appetite changes are common in depression and in PD, as well as cognitive disorders, including difficulties to concentrate and to make decision. Cognitive deficits can contribute to social withdrawn, decreased initiative, dependency and apprehension in the absence of a depressive disorder. Apathy and fatigue can present as discrete syndromes which turns the diagnostic process even more challenging.

Thus, it is still uncertain the sensitivity and specificity of classical depressive symptoms for the diagnosis of depression in PD. An 'inclusive' approach to depressive symptoms in PD would consider all symptoms as related to depression, regardless of a possible overlap with PD or other medical symptoms. This procedure could increase the sensitivity of clinical assessment, obviously at cost of specificity in the diagnosis of depression. It must be noted, however, that this 'inclusive' approach also requires validation and a careful assessment of its clinical impact. Diagnostic instruments can be useful to identify depression in PD. Researches which have used structured or semi-structured interviews diagnose depression more frequently than the ones which have used unstructured interviews'. Observer-rated instruments should be preferred as they have better psychometric properties than self-rated scales. Interestingly, self-report instruments tend to give higher prevalence of depression than observer-rated instruments ${ }^{7}$. The Hamilton Depression Rating Scale, the Beck Depression Inventory and the Montgomery-Asberg Depression Scale are some validated instruments for screening depression and for measuring severity of depressive symptoms in PD. In Brazil, two independent studies proposed that a score higher than 18 in the Beck Depression Inventory suggests a major depressive disorder ${ }^{11,12}$.

Etiology of depression in PD is not clear yet. Although a psychological component cannot be neglected, the frequency of depression in PD seems to be higher than in other chronic and debilitating diseases. The evidence that depressive symptoms in PD can antedate its motor signs by a period of 4 to 7 years gives additional support to a biological basis of depression in $\mathrm{PD}^{13}$. This period parallels the onset of neurodegeneration in substantia nigra pars compacta according to neuroimaging studies. Due to the potential role played by immune factors in the pathophysiology of both PD and depression, it is tempting to speculate that some of these depressive disorders in PD may be immune-mediated ${ }^{14}$.

There is also evidence of dopaminergic, noradrenergic, serotonergic and cholinergic dysfunction in PD depression. Post-mortem studies revealed higher loss of dopaminergic neurons in the ventral tegmentar area and of noradrenergic neurons in the locus ceruleus of depressed PD patients. Dopaminergic and noradrenergic activity seems to be diminished in limbic areas of PD patients with depression. Some studies observed reduced levels of 5-hydroxyindolacetic acid, a serotonin metabolite, in the cerebrospinal fluid of depressed patients with PD. Reduced cortical $5 \mathrm{HT}_{1 \mathrm{~A}}$ receptor binding was also noticed in these patients ${ }^{15}$. Furthermore, there are structural changes in the raphe nuclei of depressed PD patients. It is still controversial whether polymorphisms of the promoter region of the serotonin transporter gene are implicated in PD depression ${ }^{16,17}$. A cortical cholinergic impairment has been associated with depressive symptoms in PD ${ }^{18}$. Mood symptoms have also been reported in PD patients undergoing subthalamic deep brain stimulation, including increased rates of suicide attempts ${ }^{19}$.

A relevant issue regarding studies on the pathogenesis of depression in PD is that the heterogeneity of depressive syndromes in PD has been overlooked. It is possible that the spectrum of these depressive disorders has neurobiological particularities, beyond the obvious phenomenological differences. Moreover, if depressive disorders in PD differ from the ones that occur in the elderly without PD, clinical assays conducted specifically in the PD population are required to assess pharmacological efficacy and safety of antidepressants. Unfortunately, evidences concerning antidepressant treatment in PD are still limited.

A recent study observed that nortriptyline, a tricyclic antidepressant, is superior to paroxetine, a selective serotonin receptor inhibitor (SSRI), and placebo, without dif- 
ference between paroxetine and placebo ${ }^{20}$. Both active treatments were well tolerated. Other randomized placebo-controlled studies had already observed an efficacy of nortriptyline ${ }^{21}$ and a lack of efficacy of another SSRI, citalopram $^{22}$, in PD depression. A recent work compared the efficacy of desipramine, a tricyclic antidepressant with a prominent noradrenergic action, with citalopram and placebo $^{23}$. This study observed that patients in use of desipramine responded faster than the group on citalopram, although the efficacy of both drugs was superior to placebo. Whether antidepressants with a less selective mechanism of action are more effective in treating depression in PD than SSRI is still a matter of debate. In the case this hypothesis is confirmed, it corroborates the view that depression in PD is due to a widespread neurodegenerative process affecting different encephalic regions.

Physicians must be aware of a higher frequency of collateral events with tricyclic antidepressant, which may be desirable and of clinical usefulness though. For instance, tricyclic antidepressants with lower anticholinergic effects may improve tremor or drooling.

The dopaminergic agonist pramipexole is effective in treating motor signs of PD and it may also display antidepressant effects ${ }^{24}$. Its antidepressant properties were already described for PD patients and its efficacy seems to be equivalent to fluoxetine in depressed non-PD patients ${ }^{25}$. Thus pramipexole may be considered a first line drug for treating depression in PD, although further studies are still necessary. The antidepressant effect is observed with $1 \mathrm{mg} /$ day, with a maximum efficacy with $5 \mathrm{mg}$ / day at cost of increased adverse effects ${ }^{25}$.

It is worth mentioning a recent Brazilian study that demonstrated the efficacy of fish oil with omega-3 fatty acid as an antidepressant or as an adjunctive therapy for major depression in $\mathrm{PD}^{26}$. Repetitive transcranial magnetic stimulation possibly has the same antidepressant efficacy as fluoxetine and may also improve motor and cognitive performance ${ }^{27}$. Some open-label studies with other non-pharmacological interventions showed encouraging results, but deserve further investigation. Cognitivebehavioral therapy demonstrated efficacy in PD depres$\operatorname{sion}^{28}$ with some evidence supporting a cognitive model of vulnerability to depression by PD patients ${ }^{29}$. SerraMestres and Ring observed that PD patients have an illness-related vulnerability to negative emotional stimuli which could predispose to cognitive distortion that may lead to depression ${ }^{29}$. Electroconvulsive therapy may be effective in ameliorating depression in PD, although adequate evidence of its safety and efficacy are still lacking.

\section{ANXIETY}

The precise frequency of anxiety in PD is still uncertain. Nevertheless it is recognized that anxiety in PD is ex- tremely common. It has been estimated that nearly $30 \%$ of PD patients may present a generalized anxiety disorder ${ }^{30}$. By contrast some authors consider that panic disorder is the most frequent anxiety disorder in PD, with a prevalence also close to $30 \%^{31}$. According to Lauterbach and Duvoisin, the frequency of simple phobia in familial parkinsonism is $34.2 \%^{32}$. It is feasible that the most frequent anxiety disorder in PD is social anxiety disorder, as nearly $50 \%$ of PD patients can be diagnosed with social phobia ${ }^{33}$.

Anxiety in PD is associated with a worse quality of life ${ }^{4}$. Comorbidity with depressive disorders is also high. It is possible that anxiety worsens motor signs, which can reciprocally determine further anxiety ${ }^{4}$. The main feature of anxiety is the inappropriate feeling of apprehension, preoccupation or fear, but mood, cognitive, and somatic changes are also present. Some symptoms may be common to PD, such as autonomic symptoms, fatigue, muscle tension, insomnia and attention problems. Several instruments to assess anxiety were already tested in PD, but additional psychometric information is still necessary to consider these instruments valid in the context of PD.

Some anxiety disorders in PD can be comprehensible from a psychological perspective. To be diagnosed with a chronic disease, without a cure and with an inexorable course is difficult for most patients. Motor signs and changes in appearance could explain anxiety in social situations. However, the frequency of anxiety in PD seems to be higher than in other chronic diseases and unrelated to the severity of motor signs ${ }^{34}$. Even in social phobia, the phobic symptoms do not correlate with disease severity and are not restricted to performance situations ${ }^{33}$. Furthermore, as observed for depressive disorders, anxiety can precede motor signs by several years, suggesting that the neurobiological substrate of PD is responsible for the anxiety at least in part of these patients ${ }^{13}$.

The increased frequency of anxiety within this population contrasts with what occurs in the general elderly population. There is an evident decrease in the frequency of anxiety disorders in the elderly. An additional support to the hypothesis of a neurobiological substrate for anxiety in PD is that anxiety symptoms are possibly more frequent in patients with left sided motor signs ${ }^{35}$. The increased frequency of anxiety disorders in PD may be associated with changes in dopaminergic, noradrenergic, serotonergic and gabaergic pathways. PD patients with a short allele in the promoter region of the serotonin transporter gene have more anxiety than patients with the long allele variant ${ }^{16}$. Moreover, patients with PD are unusually susceptible to yohimbine-induced panic attacks ${ }^{36}$. Yohimbine is an alpha 2-adrenergic antagonist that is capable of precipitating panic attack in vulnerable individuals. It has been hypothesized that the dopaminergic deficit would disinhibit locus ceruleus firing, determining anxiety symp- 
toms. It is still controversial the relationship between panic attacks and dopaminergic drugs $s^{30,34}$, 'freezings' or motor fluctuations ${ }^{31,32}$. Nevertheless, anxiety symptoms, including panic attacks, seem to occur more frequently during 'off' periods, ameliorating when patients enter the 'on' state ${ }^{37}$.

Currently, there are no studies concerning specifically the treatment of anxiety in PD. When anxiety is associated with anti-parkinsonian treatment or with 'off' periods, reducing the dose or optimizing anti-parkinsonian treatment might improve anxiety. Unfortunately, the treatment of anxiety disorders in PD is still based on the treatment of anxiety in individuals without PD.

Benzodiazepines must be used with care for short periods in the elderly. It must be highlighted that this class of drugs can worsen cognitive and motor symptoms of PD. Buspirone has a small to moderate effect on anxiety and can ameliorate dyskinesias, but can worsen parkinsonism in higher doses ${ }^{38}$. Low doses of tricyclics with less anticholinergic effects and the SSRIs can be useful, especially when comorbid depression exists. Menza et al. recently observed a positive effect of nortriptyline on anxiety in depressed PD patients, whereas paroxetine was ineffective $^{20}$. In an open-label study from these authors, citalopram decreased anxiety in depressed PD patients ${ }^{39}$. However, it is possible that SSRI can worsen the motor signs of susceptible subjects. Theoretically, the increase in serotonergic activity inhibits the release of dopamine by the dopaminergic neurons, but it is still debatable whether this class of drugs can actually worsen extra-pyramidal signs. Psychological support, psychoeducation and counseling are other therapeutic options for anxiety in PD, but these strategies also deserve a systematic investigation.

\section{OBSESSIVE COMPULSIVE DISORDER AND PUNDING}

Repetitive behaviors in PD are important not just due to their impact for patients, but also because their phenomenology and physiopathology may help to explain obsessive-compulsive spectrum disorders. It is known that obsessive-compulsive disorder (OCD) occurs frequently in diseases that affect basal ganglia, such as Tourette's syndrome and Sydenham's chorea. Increased number of cases of OCD also occurred after an outbreak of encephalitis lethargica (von Economo encephalitis), which is clinically characterized by parkinsonism. Despite the supposed high frequency of $O C D$ in idiopathic PD, current evidences regarding OCD prevalence in PD are still divergent ${ }^{40}$.

Besides the controversy whether an association between PD and OCD exists, some interesting findings can be pointed out. Tomer et al. and Maia et al. observed that obsessive-compulsive symptoms (OCS) of contamination/ cleaning are associated with the predominance of bilateral or left-sided motor signs ${ }^{41,42}$. This finding is in line with a previous neuroimaging study which found that patients with contamination/cleaning-related OCS had greater activation of bilateral ventromedial prefrontal cortex and right caudate nucleus than controls ${ }^{43}$. Data concerning some other symptom dimensions, such as ordering/symmetry, are still inconsistent. Until now, no functional neuroimaging or neuropathological study evaluated whether OCS in PD could reflect an asymmetric dopaminergic deficiency, as proposed by Tomer et al.

Individuals with PD may also share a particular personality profile. This personality profile includes features such as low novelty seeking behavior and high harm avoidance, less predisposition to addiction, shyness, introspectiveness, morality, inflexibility and lower expression of an$\operatorname{ger}^{40}$. Nonetheless, some studies argue against the existence of a "parkinsonian personality" 44 . It is still necessary to investigate the relationship between obsessivecompulsive phenomena and age of PD onset, characteristics of motor signs, duration and severity of the disease and its treatment.

Dopaminergic therapy has been associated with repetitive behaviors in PD since 1994, when the first case of punding due to levodopa was described ${ }^{45}$. Punding is a behavior described as repetitive, stereotyped and purposeless. A wide range of behaviors has been characterized as punding, including hoarding, shuffling papers, sorting labels, assembling and disassembling objects, skin picking, increased writing activity, wandering, humming and among others. According to some, punding is phenomenological and biologically distinct from $\mathrm{OCD}^{46}$. The behaviors observed in punding are related to the person's previous work or hobby experiences. They are considered by the patients as fascinating and soothing, leading to social withdrawn and interpersonal problems. The repetitive behaviors of $O C D$ are generally a response to cognitive intrusions (obsessions) and the associated anxiety, which are absent in punding. In addition, the main symptomatic domains in OCD (checking, religious and sexual OCS; symmetry and ordering; contamination and cleaning) are evolutionarily related to social and territorial concerns, focusing on themes of violence, hygiene and sex. Thus, OCD is due to implicit processing deficits reflected in the aberrant processing of species-specific procedural strategies, probably stored within the striatum. On the other hand, punding reflects an aberrant processing of learning procedural strategies from past experience ${ }^{46}$. The prevalence of punding in PD is estimated to be nearly $1.4 \%$. However, in patients in use of high doses of dopaminergic dugs, the frequency is close to $14 \%{ }^{48}$. Dopaminergic agonists seem to be especially related to punding ${ }^{49}$. Additional associated factors are young onset of disease, higher impulsivity and worse quality of life ${ }^{49}$. As discussed below, predictors of punding, dopamine dysregulation syndrome (DDS) 
and impulse control disorders in the context of PD are superimposed.

There are no systematic studies on the pharmacological therapy for OCD and punding in PD. Fortunately, it seems that the majority of cases of OCD in PD is not clinically relevant, and pharmacological intervention is not necessary. If the emergence of a repetitive behavior is obviously related to the introduction or increase in dosage of a drug, the good clinical practice demands that such drug must be decreased or withdrawn.

\section{IMPULSE CONTROL DISORDERS AND DOPAMINE DYSREGULATION SYNDROME}

Impulse control disorders (ICD) are a group of disorders which is characterized by the failure to resist to an impulse, drive or temptation to perform an act that is harmful (physically, psychologically, socially, legally or financially) to the person or to others. In the context of PD, the ICDs are generally associated with dopaminergic therapy. The nosography of the ICDs is open to a debate, as most of the ICDs (pathological gambling, compulsive shopping, hypersexuality, compulsive eating), as well as dopamine dysregulation syndrome (DDS), are addictive behaviors. On the other hand, part of the phenomenology of the ICDs resembles OCD. Hence, the extent to which ICDs constitute a homogeneous group is unclear.

Recent studies have shown that ICDs in PD are quite common. Approximately $6 \%$ of PD patients fulfill diagnostic criteria for ICD, and this frequency is even higher $(13.7 \%)$ in patients in use of dopaminergic agonists ${ }^{50}$. Risk factors for an ICD in PD are early onset of the disease ${ }^{51}$, younger age ${ }^{51}$, high doses of dopaminergic drugs (especially the dopaminergic agonists) $)^{5,52}$, and a history of psychiatric disorder, ICD or recreational drug or alcohol use ${ }^{52}$.

In most cases, physicians can easily observe an association between the emergence of an ICD and the introduction or the increase in dosage of an antiparkinsonian $\mathrm{drug}^{53}$. Even when the period of time between these events is longer, a decrease in dosages may benefit the patient ${ }^{53}$. A long-term follow-up study of PD patients with ICD demonstrated that the withdraw or dose reduction of dopaminergic agonists resolved most cases, even if the levodopa dosage was increased to control motor signs ${ }^{54}$. However, despite the initial supposition that some dopaminergic agonists were more frequently related to ICDs than others, it seems that such a difference does not exist ${ }^{52,55}$.

Pathological gambling, a failure to resist the impulse to gamble despite severe psychosocial consequences, is associated with an early onset of disease, high novelty seeking behavior, personal or familiar history of alcoholism and dopaminergic therapy ${ }^{55}$. Gambling occurs almost exclusively during 'on' periods ${ }^{56}$. Hypersexuality, an exaggerated sexual behavior, has been associated with dopaminer- gic agonists, but it can also occur when patients are in use of levodopa or subthalamic deep brain stimulation. The changes in sexuality include spontaneous penile erections, increased libido and new sexual habits which dramatically contrast with personal history ${ }^{57}$. Marital and legal problems are common among these patients. Compulsive buying is a preoccupation, urge or impulsive behavior related to buying or shopping. This behavior is maladaptive and has significant psychosocial consequences. Most cases of compulsive shopping also occur in patients in use of dopaminergic agonists. Compulsive eating is the ingestion of a large amount of food in a short period of time and a sensation of lack of control over eating. Although compulsive eating may also be associated with dopaminergic drugs, most of these patients were already overweight previously to the disorder emergence ${ }^{58}$. The lack of insight by some patients and the fact that these patients usually feel guilty, and thus seldom report their symptoms, turn the identification of the ICDs very difficult.

Frequently, the ICDs occur in the context of a recently described syndrome. The DDS, initially named hedonistic homeostatic dysregulation, is the overuse of dopaminergic drugs beyond that needed to relieve motor signs and in spite of the consequent disabling dyskinesias and behavioral disorders. The diagnostic criteria for DDS were defined by Pezzella et al. ${ }^{59}$

Risk factors associated with DDS are similar to the ones associated with $I C D s^{60}$. There is usually a long latency between the beginning of levodopa treatment and the onset of drug misuse, and fast acting drugs are more likely associated with $D^{2}{ }^{61}$. The availability of drugs seems to be relevant, and that is probably why DDS is uncommon among PD patients from the Brazilian public health system, where access to dopaminergic drugs is under restrict control of the State.

The study of ICDs and DDS in PD highlights the role of dopamine in behavioral modulation and reward system. Both the ventral and dorsal striatum have been implicated in the reward system. Ventral striatum possibly mediates psychomotor stimuli from dopaminergic drugs and their primarily reinforcing effects. Patients with DDS have a more intense dopamine release in ventral striatum induced by levodopa than PD patients in use of levodopa without $\mathrm{DDS}^{62}$. It is unclear whether this alteration is due to sensitization of ventral striatum or if it is constitutional of these individuals and expressed by a pronounced novelty seeking trait ${ }^{62}$.

Despite the limited evidence regarding therapy of ICD and DDS, it is generally indicated adjustment of dopaminergic therapy, behavioral and pharmacological therapy used in ICD without PD, and psychosocial support ${ }^{63}$. These patients present a challenge to the clinician ${ }^{64}$. There are case reports of successful treatment of ICD in DP with clo- 
zapine, quetiapine, valproate, lithium, topiramate, donepezil, amantadine, cyproterone (for hypersexuality), and deep brain stimulation ${ }^{65}$. Paradoxically, it has also been described behavioral complications of several of these therapies, including overuse of deep brain stimulation ${ }^{66}$.

\section{PYCHOTIC SYMPTOMS}

Psychosis in PD is frequently conceptualized as the presence of distortions of thought (delusions), sensoperception (illusions and hallucinations) and dreams (vivid dreams). Recently, the National Institute of Mental Health (NIMH) proposed criteria for psychosis in PD ${ }^{67}$. Psychotic symptoms are considered the most frequent psychiatric complication associated with antiparkinsonian treatment ${ }^{1}$, although psychosis in PD was already described in the pre-levodopa era.

Prevalence of psychosis in PD in the community ranges between 15 and $20 \%$. Hallucinations with preserved insight are the most common psychotic symptoms ${ }^{68}$. Vivid dreams may occur in up to $55 \%$ of PD patients in tertiary centers ${ }^{69}$. A recent review of studies which investigated the frequency of psychosis in PD (according to the NIMH criteria) concluded that its point-prevalence is close to $23 \%{ }^{70}$.

Complex visual hallucinations are the most common type of hallucinatory phenomena ${ }^{71-73}$. Patients are more frequently the observer rather than the actor of a hallucinated scene. Simple visual hallucinations are unusual. Illusions, passage hallucinations (seeing someone or something passing-by oneself for a fleeting moment) and sense of presence (sensation of the presence of somebody) are also frequent ${ }^{71}$. Auditory hallucinations can be simple (ringing, knocking or buzzing sounds) or, more often, complex (voices or music). The complex auditory hallucinations in PD differ, however, from the pejorative or threatening ones characteristic of schizophrenia. Visual hallucination in PD resemble the ones that occur in the visually impaired (Charles Bonnet syndrome) ${ }^{72}$. Indeed, impaired visual acuity is a risk factor for visual hallucinations in $\mathrm{PD}^{73}$, which are also more frequent in the evening than during the night ${ }^{71}$. Thus, complex visual hallucinations are probably associated with abnormal activity in the ventral extrastriatal visual cortex, but several other models have been proposed to explain the different psychotic phenomena that may emerge in $\mathrm{PD}^{74}$. Atypical hallucinations (tactile, olfactory or gustatory) can also occur, but they are less often.

Age can influence the psychotic phenomena. Patients with earlier onset of PD and of psychosis frequently experience more delusions than patient with a later onset, in whom hallucinatory phenomena are more often ${ }^{75}$. Moreover, older patients are more likely to have non-visual or combined hallucinations than pure visual hallucinations ${ }^{76}$.
Patients cognitively intact usually preserve their insight. Cognitive decline and depression are the main predictors of psychosis ${ }^{68}$. Additional risk factors are advanced age, longer disease duration, daytime sleepiness and sleep disorders and a more severe disease $\mathrm{e}^{30,69,71,73,77}$.

It is worth mentioning that PD may occur in patients with a previous primary psychotic disorder. Due to the simplistic models of dopaminergic hyperactivity in schizophrenia, it was believed that individuals with this disorder were less prone to develop PD. However, there is no scientific evidence that support this belief. In fact, the diagnosis in these cases is difficult because patients with schizophrenia are in use of antipsychotic for many years. For differential diagnosis between drug induced parkinsonism and PD in schizophrenia, when drug withdrawn is not possible, presynaptic dopamine transporter neuroimaging (e.g., FP-CIT SPECT) may be helpful ${ }^{78}$. Dopaminergic replacement therapy may reestablish patient's functionality without worsening of psychotic symptoms ${ }^{79}$.

Psychosis is the main predictor of institutionalization of patients with $\mathrm{PD}^{80}$ and is associated with increased mortality ${ }^{81}$. Hence, it is essential an adequate assessment of these cases. First, delirium must be ruled out. Then, simple non-pharmacological interventions might be initially tried and they can resolve many cases. These interventions include sleep hygiene, correction of sensorial overstimulation or deprivation, and orientation to patients and their family. If the disorder persists, antiparkinsonian treatment should be simplified. When the introduction of a new drug is clearly related to the psychosis onset, this drug must be withdrawn. Then, anti-parkinsonian drugs should be withdrawn according to their potential to induce psychosis.

Physicians are often worried with the possibility of worsening motor signs due to antipsychotics. Clozapine improve significantly psychosis without worsening motor signs $^{82,83}$. In fact, clozapina is the only antipsychotic with established efficacy based on randomized placebo-controlled trials ${ }^{84-86}$. Clozapine may also decrease dyskine$\operatorname{sias}^{87}$, but it has low tolerability among elderly with $\mathrm{PD}^{83}$. Hence, clozapine must be used judiciously in elderly patients. Quetiapine is an alternative for clozapine when this drug is not tolerated ${ }^{82}$. Olanzapine and risperidone can improve psychosis in PD, but at cost of relevant worsening of motor signs. Alternative therapies include anticholinesterasic drugs $^{88}$, ondansetron ${ }^{89}$ and cannabidiol ${ }^{90}$, which presented interesting results in open-label studies with good tolerability.

\section{SLEEP DISORDERS}

Sleep disorders are the most prevalent non-motor symptoms in PD. Nearly 80 to $90 \%$ of PD patients have some type of sleep difficulty ${ }^{91}$, and virtually all patients 
with PD will experience a sleep disorder during the course of the disease ${ }^{3}$. Sleep disorders may be caused by a series of factors including degeneration of sleep regulatory centers in the brainstem and thalamo-cortical pathways, drug effects or due to PD symptoms affecting the normal sleep, such as the motor impairment, depressive and anxiety disorders, and bladder incontinency.

Some sleep disorders may precede the onset of motor symptoms. Schenck et al. noticed that many patients diagnosed with REM sleep behavior disorder developed parkinsonism a few years later ${ }^{92}$. The REM sleep behavior disorder, which occurs in almost a third of PD patients ${ }^{92}$, is often associated with cognitive impairment and hallucinations ${ }^{93}$. This disorder is directly related to the degenerative process of the pedunculopontine nucleus, the locus subceruleus and the retrorubral nucleus, which affect normal REM atonia and phasic generator circuitry ${ }^{3}$. A sudden onset of the disorder is almost always due to the introduction or the withdrawn of a drug, especially antidepressants $^{94}$. Curiously, parkinsonism can disappear during the REM sleep behavior disorder. Some authors reported an impressive improvement of bradykinesia, tremor, dystonias, speech and mimic during the phenomenon ${ }^{93}$.

Sleep fragmentation is the earliest and most common sleep disorder in PD, and it gradually worsens with disease progression ${ }^{91}$. Vivid dreaming, nightmares and night terrors are also common and may occur in up to $30 \%$ of patients in chronic use of levodopa ${ }^{95}$. It is possible that even dream content is altered in PD. Borek et al. observed that patients with PD and REM sleep behavior disorder frequently report dreams of being chased, of defending themselves against attacks or with aggressive content ${ }^{96}$. Many patients vocalize during sleep. The vocalization content may vary from incomprehensible sounds to detailed conversations, laughing, cursing or screaming ${ }^{94}$.

Excessive daytime sleepiness and 'sleep attacks' affect half of patients with PD and can also precede disease onset $^{3}$. The causes are a combination of the disease process, the consequence of other sleep disorders and medications. A sudden onset of sleep during the day is a phenomenon in PD which resembles narcolepsy, and it is commonly associated with dopaminergic drugs.

It is possible that PD patients are also more prone to other sleep disorders such as restless legs syndrome, periodic limb movements and obstructive sleep apnea.

Sleep disorders in PD are seldom diagnosed and treated. The use of clinimetric instruments such as the Parkinson's Disease Sleep Scale or the Epworth Sleepiness Scale may help to identify these disorders. Although an accurate diagnosis of sleep disorder depends on polysomnography, some of them can be diagnosed clinically. Treatment is based on a correct diagnosis of the sleep disorder or its cause. Sometimes it is difficult to decide whether an excessive daytime sleepiness is cause or consequence of insomnia. Sleep hygiene is the initial and basic measure applied to all patients. For instance, stimulating patients during the day can decrease the excessive naps and improve sleep at night, thus improving daytime sleepiness. Additional techniques include going to bed only when sleepy, exposure to natural and bright light during day, reduction of light and noise exposure at night as much as possible, and maintenance of a regular schedule.

Long-acting dopaminergic drugs might improve insomnia caused by worsening of motor symptoms at night. Benzodiazepines (e.g. clonazepam) can help patients with difficulty to initiate sleep or with REM sleep behavior disorder. The Continuous Positive Airway Pressure is the only effective treatment for obstructive sleep apnea. Antidepressants with a sedative effect might be helpful in cases of insomnia with comorbid depression or anxiety. Low doses of amitryptiline may be useful in cases of nocturia. Small clinical trials with modafinil for excessive daytime sleepiness had controversial results ${ }^{97}$. An additional remark concerning treatment of sleep disorder in PD is that sleep may provide a short-term benefit on motor symptoms ${ }^{98}$.

\section{APATHY AND FATIGUE}

Apathy and fatigue are considered two independent syndromes, which are difficult to distinguish from depressive disorders and excessive daytime sleepiness. Fatigue is defined as a sense of tiredness, lack or energy or exhaustion, which can be mental or physical. Although this sense of tiredness can be due to a hard work, the studies on fatigue are concerned with the subjective (or central) phenomena. Apathy is a syndrome with motivational, emotional, cognitive and behavioral characteristics. They include a reduced interest and participation in daily activities, a lack of initiative and difficulty in sustaining an activity to completion, lack of concern or indifference, and a flattening of affect ${ }^{99}$. Between $16 \%$ and $42 \%$ of PD patients report apathy ${ }^{100,101}$. The frequency of fatigue is close to $42 \%$ in PD patients ${ }^{102}$.

The pathophysiology of these syndromes is poorly understood. A fronto-striatal disruption is probably related to apathy ${ }^{100}$. Indeed, apathetic PD patients have worse cognitive performance, especially of executive functions, than non-apathetic patients ${ }^{103}$. The association between cognition and apathy, along with the potential benefit of anticholinesterasic drugs on both cognition and apathy, suggests that cholinergic mechanisms take part in the pathophysiology of apathy ${ }^{99,100}$.

On the other side, a mitochondrial malfunction or the increased metabolic rate of PD, due to muscular rigidity or neuroinflammatory mechanisms, may be the causes of fatigue $^{104}$. The poor response to dopaminergic therapy suggests that other pathways are possibly involved. 
Regarding the treatment of apathy and fatigue, evidence is scarce. Methylphenidate has been described as effective in both conditions ${ }^{105,106}$, but more studies are necessary. Antidepressants are not effective, can cause unnecessary side effects and can even aggravate apathy ${ }^{107}$, demonstrating that these syndromes are really independent.

\section{COGNITIVE IMPAIRMENT AND DEMENTIA}

Cognitive impairment in different domains (executive functions, processing speed, attention, memory, visuospatial functioning) are observed even in the initial stages of PD when patients have not developed dementia yet. The prevalence of dementia in PD vary between 24 to $31 \%{ }^{108}$. The presence of dementia is associated with increased risk of institutionalization ${ }^{80}$ and increased mortality ${ }^{6}$. Risk factors for dementia include advanced age, a later onset of disease, longer disease duration, rigid-akinetic PD variant, severity of motor signs, depression, psychosis and atypical neurological signs ${ }^{109}$.

Impairment in executive functioning is the most common cognitive deficit in $\mathrm{PD}^{110}$. Memory difficulties are also common and free recall is more affected than learning new information (memory storage) in contrast with Alzheimer's disease. Indeed dementia in PD is traditionally regarded as a subcortical dementia. Furthermore, a bad cognitive performance on tasks with a more posterior cortical basis, such as semantic fluency and pentagons drawing, are predictors of dementia in $\mathrm{PD}^{110}$. Cognitive impairment secondary to a comorbid neuropsychiatric disorder, such as depression and Alzheimer's disease, may superimpose to those typically seen in PD dementia, turning difficult the diagnostic process. It is worth mentioning that patients with low educational level are particularly susceptible to the deleterious effect of depression on cognition"1".

Recently, the Movement Disorders Society operationalized the diagnosis of PD dementia. In a first moment, a clinician without expertise in neuropsychological assessment could use simple, short and pragmatic set of tests to diagnose PD dementia ${ }^{112}$. If dementia diagnosis remains uncertain or equivocal, or if a rigorous clinical monitoring is required, a formal neuropsychological assessment may be requested.

Antiparkinsonian drugs such as anti-cholinergics and amantadine may induce confusional states and worse cognitive deficits. On the other hand, anticholinesterasics can improve cognitive performance and behavioral disorders associated with dementia in $\mathrm{PD}^{113}$.

In conclusion, neuropsychiatric disorders are common in PD, but not frequently recognized by clinicians. The assessment of these conditions must be routinely conducted due to their impact on the motor signs and on the quality of life of patients and caregivers. The treatment for most of these disorders still lacks scientific evidence. Future studies must focus on elucidating their pathophysiology and on the development of treatment strategies for these syndromes.

\section{REFERENCES}

1. Schrag A. Psychiatric aspects of Parkinson's disease: an update. J Neurol 2004;251:795-804.

2. Scalzo P, Kummer A, Cardoso F, Teixeira AL. Depressive symptoms and perception of quality of life in Parkinson's disease. Arq Neuropsiquiatr 2009;67:203-208.

3. Chaudhuri KR, Healy DG, Schapira AH. Non-motor symptoms of Parkinson's disease: diagnosis and management. Lancet Neurol 2006;5: 235-245.

4. Rahman S, Griffin HJ, Quinn NP, Jahanshahi M. Quality of life in Parkinson's disease: the relative importance of the symptoms. Mov Disord 2008;23:1428-1434.

5. Schrag A, Jahanshahi M, Quinn N. What contributes to quality of life in patients with Parkinson's disease? J Neurol Neurosurg Psychiatry 2000;69:308-312

6. Hughes TA, Ross HF, Mindham RH, Spokes EG. Mortality in Parkinson's disease and its association with dementia and depression. Acta Neurol Scand 2004;110:118-123.

7. Reijnders JS, Ehrt U, Weber WE, Aarsland D, Leentjens AF. A systematic review of prevalence studies of depression in Parkinson's disease. Mov Disord 2008;23:183-189.

8. Stella F, Banzato CE, Barasnevicius Quagliato EM, Viana MA. Depression in patients with Parkinson's disease: impact on functioning. J Neurol Sci 2008;272:158-163.

9. Richard IH, Justus AW, Kurlan R. Relationship between mood and motor fluctuations in Parkinson's disease. J Neuropsychiatry Clin Neurosci 2001;13:35-41.

10. The Global Parkinson's Disease Survey (GPDS) Steering Committee. Factors impacting on quality of life in Parkinson's disease: results from an international survey. Mov Disord 2002;17:60-67.

11. Silberman CD, Laks J, Capitao CF, Rodrigues CS, Moreira I, Engelhardt E. Recognizing depression in patients with Parkinson's disease: accuracy and specificity of two depression rating scale. Arq Neuropsiquiatr 2006;64:407-411.

12. Tumas V, Rodrigues GG, Farias TL, Crippa JA. The accuracy of diagnosis of major depression in patients with Parkinson's disease: a comparative study among the UPDRS, the geriatric depression scale and the Beck depression inventory. Arq Neuropsiquiatr 2008;66:152-156.

13. Shiba M, Bower JH, Maraganore DM, et al. Anxiety disorders and depressive disorders preceding Parkinson's disease: a case-control study. Mov Disord 2000;15:669-677.

14. Kummer A, Teixeira AL. Depressive disorders in Parkinson's disease may be due to a shared immune-mediated neurodegenerative process. Med Hypotheses 2008;70:201-202.

15. Doder M, Rabiner EA, Turjanski N, Lees A, Brooks DJ. Brain serotonin 5HT1A receptors in Parkinson's disease with and without depression measured by positron emission tomography with 11C-WAY 10635. Mov Disord 2000;15:213.

16. Menza MA, Palermo B, DiPaola R, Sage JI, Ricketts MH. Depression and anxiety in Parkinson's disease: possible effect of genetic variation in the serotonin transporter. J Geriatr Psychiatry Neurol 1999;12:49-52.

17. Dissanayaka NN, Silburn PA, O'Sullivan JD, Mellick GD. Serotonin and dopamine transporter genes do not influence depression in Parkinson's disease. Mov Disord 2009;24:111-115.

18. Bohnen NI, Kaufer DI, Hendrickson R, Constantine GM, Mathis CA, Moore RY. Cortical cholinergic denervation is associated with depressive symptoms in Parkinson's disease and parkinsonian dementia. J Neurol Neurosurg Psychiatry 2007;78:641-643.

19. Voon V, Krack P, Lang AE, et al. A multicentre study on suicide outcomes following subthalamic stimulation for Parkinson's disease. Brain 2008;131:2720-2728. 
20. Menza M, Defronzo Dobkin R, Marin H, et al. A controlled trial of antidepressants in patients with Parkinson disease and depression. Neurology 2009;72:886-892.

21. Andersen J, Aabro E, Gulmann N, Hjelmsted A, Pedersen HE. Anti-depressive treatment in Parkinson's disease. A controlled trial of the effect of nortriptyline in patients with Parkinson's disease treated with L-DOPA. Acta Neurol Scand 1980;62:210-219.

22. Wermuth L, Sorensen PS, Timm B, et al. Depression in idiopathic Parkinson's disease treated with citalopram. Nordic J Psychiatry 1998;52: 163-169.

23. Devos D, Dujardin K, Poirot I, et al. Comparison of desipramine and citalopram treatments for depression in Parkinson's disease: a double-blind, randomized, placebo-controlled study. Mov Disord 2008;23:850-857.

24. Kano O, Ikeda K, Kiyozuka T, et al. Beneficial effect of pramipexole for motor function and depression in Parkinson's disease. Neuropsychiatr Dis Treat 2008;4:707-710.

25. Corrigan MH, Denahan AQ, Wright CE, Ragual RJ, Evans DL. Comparison of pramipexole, fluoxetine, and placebo in patients with major depression. Depress Anxiety 2000;11:58-65.

26. Silva TM, Munhoz RP, Alvarez C, et al. Depression in Parkinson's disease: a double-blind, randomized, placebo-controlled pilot study of omega-3 fatty-acid supplementation. J Affect Disord 2008;111:351-359.

27. Fregni F, Santos CM, Myczkowski ML, et al. Repetitive transcranial magnetic stimulation is as effective as fluoxetine in the treatment of depression in patients with Parkinson's disease. J Neurol Neurosurg Psychiatry 2004;75:1171-1174.

28. Dobkin RD, Allen LA, Menza M. Cognitive-behavioral therapy for depression in Parkinson's disease: a pilot study. Mov Disord 2007;22: 946-952.

29. Serra-Mestres J, Ring HA. Evidence supporting a cognitive model of depression in Parkinson's disease. J Nerv Ment Dis 2002;190:407-410.

30. Kummer A, Cardoso F, Teixeira AL. Frequency of psychiatric disorders in young-onset Parkinson's disease does not differ from typical-onset Parkinson's disease. Parkinsonism Relat Disord 2009;15:153-155.

31. Lauterbach EC, Freeman A, Vogel RL. Correlates of generalized anxiety and panic attacks in dystonia and Parkinson disease. Cogn Behav Neurol 2003;16:225-233.

32. Lauterbach EC, Duvoisin RC. Anxiety disorders in familial parkinsonism. Am J Psychiatry 1991;148:274.

33. Kummer A, Cardoso F, Teixeira AL. Frequency of social phobia and psychometric properties of the Liebowitz social anxiety scale in Parkinson's disease. Mov Disord 2008;23:1739-1743.

34. Stein MB, Heuser IJ, Juncos JL, Uhde TW. Anxiety disorders in patients with Parkinson's disease. Am J Psychiatry 1990;147:217-220.

35. Fleminger S. Left-sided Parkinson's disease is associated with greater anxiety and depression. Psychol Med 1991;21:629-638.

36. Kurlan R, Lichter D, Schiffer RB. Panic/anxiety in Parkinson's disease: yohimbine challenge [abstract]. Neurology 1989;39:421.

37. Siemers ER, Shekhar A, Quaid K, Dickson H. Anxiety and motor performance in Parkinson's disease. Mov Disord 1993;8:501-506.

38. Walsh K, Bennett G. Parkinson's disease and anxiety. Postgrad Med J 2001;77:89-93.

39. Menza M, Marin H, Kaufman K, Mark M, Lauritano M. Citalopram treatment of depression in Parkinson's disease: the impact on anxiety, disability, and cognition. J Neuropsychiatry Clin Neurosci 2004;16:315-319.

40. Kummer A, Teixeira AL. Parkinson's disease and obsessive-compulsive phenomena: a systematic review. Curr Psychiatry Rev 2009;5:55-61.

41. Maia AF, Pinto AS, Barbosa ER, Menezes PR, Miguel EC. Obsessivecompulsive symptoms, obsessive-compulsive disorder, and related disorders in Parkinson's disease. J Neuropsychiatry Clin Neurosci 2003;15:371-374.

42. Tomer R, Levin B, Weiner W. Obsessive-compulsive symptoms and motor asymmetries in Parkinson's disease. Neuropsychiatry Neuropsychol Behav Neurol 1993;6:26-30.

43. Mataix-Cols D, Wooderson S, Lawrence N, Brammer MJ, Speckens A, Phillips ML. Distinct neural correlates of washing, checking, and hoarding symptom dimensions in obsessive-compulsive disorder. Arch Gen Psychiatry 2004;61:564-576.
44. Glosser G, Clark C, Freundlich B, Kliner-Krenzel L, Flaherty P, Stern M. A controlled investigation of current and premorbid personality: characteristics of Parkinson's disease patients. Mov Disord 1995;10:201-206.

45. Friedman JH. Punding on levodopa. Biol Psychiatry 1994;36:350-351.

46. Voon V. Repetition, repetition, and repetition: compulsive and punding behaviors in Parkinson's disease. Mov Disord 2004;19:367-370.

47. Miyasaki JM, Al Hassan K, Lang AE, Voon V. Punding prevalence in Parkinson's disease. Mov Disord 2007;22:1179-1181.

48. Evans AH, Katzenschlager R, Paviour D, et al. Punding in Parkinson's disease: its relation to the dopamine dysregulation syndrome. Mov Disord 2004;19:397-405.

49. Lawrence AJ, Blackwell AD, Barker RA, et al. Predictors of punding in Parkinson's disease: results from a questionnaire survey. Mov Disord 2007;22:2339-2345.

50. Voon V, Hassan K, Zurowski M, et al. Prevalence of repetitive and rewardseeking behaviors in Parkinson disease. Neurology 2006;67:1254-1257.

51. Ondo WG, Lai D. Predictors of impulsivity and reward seeking behavior with dopamine agonists. Parkinsonism Relat Disord 2008;14:28-32.

52. Weintraub D, Siderowf AD, Potenza MN, et al. Association of dopamine agonist use with impulse control disorders in Parkinson disease. Arch Neurol 2006;63:969-973.

53. Dodd ML, Klos KJ, Bower JH, Geda YE, Josephs KA, Ahlskog JE. Pathological gambling caused by drugs used to treat Parkinson disease. Arch Neurol 2005;62:1377-1381.

54. Mamikonyan E, Siderowf AD, Duda JE, et al. Long-term followup of impulse control disorders in Parkinson's disease. Mov Disord 2008;23:75-80.

55. Voon V, Hassan K, Zurowski M, et al. Prospective prevalence of pathologic gambling and medication association in Parkinson disease. Neurology 2006;66:1750-1752.

56. Molina JA, Sainz-Artiga MJ, Fraile A, et al. Pathologic gambling in Parkinson's disease: a behavioral manifestation of pharmacologic treatment? Mov Disord 2000;15:869-872.

57. Klos KJ, Bower JH, Josephs KA, Matsumoto JY, Ahlskog JE. Pathological hypersexuality predominantly linked to adjuvant dopamine agonist therapy in Parkinson's disease and multiple system atrophy. Parkinsonism Relat Disord 2005;11:381-386.

58. Nirenberg MJ, Waters C. Compulsive eating and weight gain related to dopamine agonist use. Mov Disord 2006;21:524-529.

59. Pezzella FR, Colosimo C, Vanacore N, et al. Prevalence and clinical features of hedonistic homeostatic dysregulation in Parkinson's disease. Mov Disord 2005;20:77-81.

60. Evans AH, Lawrence AD, Potts J, Appel S, Lees AJ. Factors influencing susceptibility to compulsive dopaminergic drug use in Parkinson disease. Neurology 2005;65:1570-1574.

61. Sanchez-Ramos J. The straight dope on addiction to dopamimetic drugs. Mov Disord 2002;17:223-225.

62. Evans AH, Pavese N, Lawrence AD, et al. Compulsive drug use linked to sensitized ventral striatal dopamine transmission. Ann Neurol 2006;59:852-858.

63. Potenza MN, Voon V, Weintraub D. Drug Insight: impulse control disorders and dopamine therapies in Parkinson's disease. Nat Clin Pract Neurol 2007;3:664-672.

64. Kummer A, Maia DP, Salgado JV, Cardoso FE, Teixeira AL. Dopamine dysregulation syndrome in Parkinson's disease: case report. Arq Neuropsiquiatr 2006;64:1019-1022.

65. Lim SY, Evans AH, Miyasaki JM. Impulse control and related disorders in Parkinson's disease: review. Ann N Y Acad Sci 2008;1142:85-107.

66. Morgan JC, diDonato CJ, Iyer SS, Jenkins PD, Smith JR, Sethi KD. Selfstimulatory behavior associated with deep brain stimulation in Parkinson's disease. Mov Disord 2006;21:283-285.

67. Ravina B, Marder K, Fernandez HH, et al. Diagnostic criteria for psychosis in Parkinson's disease: report of an NINDS, NIMH Work Group. Mov Disord 2007;22:1061-1068

68. Aarsland D, Larsen JP, Cummins JL, Laake K. Prevalence and clinical correlates of psychotic symptoms in Parkinson disease: a communitybased study. Arch Neurol 1999;56:595-601.

69. Verbaan D, van Rooden SM, Visser M, Marinus J, Emre M, van Hilten 
JJ. Psychotic and compulsive symptoms in Parkinson's disease. Mov Disord 2009;24:738-744.

70. Holt RJ. Estimate of point prevalence of Parkinson's disease induced psychosis in the United States. Mov Disord 2008;23:1788-1789.

71. Fenelon G, Mahieux F, Huon R, Ziegler M. Hallucinations in Parkinson's disease: prevalence, phenomenology and risk factors. Brain 2000;123:733-745.

72. Barnes J, David AS. Visual hallucinations in Parkinson's disease: a review and phenomenological survey. J Neurol Neurosurg Psychiatry 2001;70:727-733.

73. Holroyd S, Currie L, Wooten GF. Prospective study of hallucinations and delusions in Parkinson's disease. J Neurol Neurosurg Psychiatry 2001;70:734-738

74. Fenelon G. Psychosis in Parkinson's disease: phenomenology, frequen$\mathrm{cy}$, risk factors, and current understanding of pathophysiologic mechanisms. CNS Spectr 2008;13:18-25.

75. Kiziltan G, Ozekmekci S, Ertan S, Ertan T, Erginoz E. Relationship between age and subtypes of psychotic symptoms in Parkinson's disease. J Neurol 2007;254:448-452.

76. Goetz CG, Wuu J, Curgian L, Leurgans S. Age-related influences on the clinical characteristics of new-onset hallucinations in Parkinson's disease patients. Mov Disord 2006;21:267-270.

77. Sanchez-Ramos JR, Ortoll R, Paulson GW. Visual hallucinations associated with Parkinson disease. Arch Neurol 1996;53:1265-1268.

78. Habermeyer B, Kneifel S, Lotz-Blauer I, Muller-Spahn F. Psychosis in a case of schizophrenia and Parkinson's disease. J Neuropsychiatry Clin Neurosci 2008;20:373-375

79. Kummer A, Castro M, Lauar H, Cardoso F, Teixeira AL. [Schizoaffective disorder and Parkinsons disease: a possible comorbidity?]. Rev Psiquiatr Clín 2006;33:28-31.

80. Aarsland D, Larsen JP, Tandberg E, Laake K. Predictors of nursing home placement in Parkinson's disease: a population-based, prospective study. J Am Geriatr Soc 2000;48:938-942.

81. Goetz CG, Stebbins GT. Mortality and hallucinations in nursing home patients with advanced Parkinson's disease. Neurology 1995;45: 669-671.

82. Merims D, Balas M, Peretz C, Shabtai H, Giladi N. Rater-blinded, prospective comparison: quetiapine versus clozapine for Parkinson's disease psychosis. Clin Neuropharmacol 2006;29:331-337.

83. Gomide L, Kummer A, Cardoso F, Teixeira AL. Use of clozapine in Brazilian patients with Parkinson's disease. Arq Neuropsiquiatr 2008;66: 611-614.

84. Pollak P, Tison F, Rascol O, et al. Clozapine in drug induced psychosis in Parkinson's disease: a randomised, placebo controlled study with open follow up. J Neurol Neurosurg Psychiatry 2004;75:689-695.

85. The French Clozapine Parkinson Study Group. Clozapine in drug-induced psychosis in Parkinson's disease. The French Clozapine Parkinson Study Group. Lancet 1999;353:2041-2042.

86. The Parkinson Study Group. Low-dose clozapine for the treatment of drug-induced psychosis in Parkinson's disease. The Parkinson Study Group. N Engl J Med 1999;340:757-763.

87. Durif F, Debilly B, Galitzky M, et al. Clozapine improves dyskinesias in Parkinson disease: a double-blind, placebo-controlled study. Neurology 2004;62:381-388.

88. Bergman J, Lerner V. Successful use of donepezil for the treatment of psychotic symptoms in patients with Parkinson's disease. Clin Neuropharmacol 2002;25:107-110.

89. Zoldan J, Friedberg G, Livneh M, Melamed E. Psychosis in advanced Parkinson's disease: treatment with ondansetron, a 5-HT3 receptor antagonist. Neurology 1995;45:1305-1308.
90. Zuardi A, Crippa J, Hallak J, et al. Cannabidiol for the treatment of psychosis in Parkinson's disease. J Psychopharmacol 2008;In press.

91. Oerlemans WG, de Weerd AW. The prevalence of sleep disorders in patients with Parkinson's disease. A self-reported, community-based survey. Sleep Med 2002;3:147-149.

92. Schenck $\mathrm{CH}$, Mahowald MW. REM sleep behavior disorder: clinical, developmental, and neuroscience perspectives 16 years after its formal identification in Sleep. Sleep 2002;25:120-138.

93. Arnulf I, Leu S, Oudiette D. Abnormal sleep and sleepiness in Parkinson's disease. Curr Opin Neurol 2008;21:472-477.

94. Friedman JH, Millman RP. Sleep disturbances and Parkinson's disease. CNS Spectr 2008;13:12-17.

95. Sharf B, Moskovitz C, Lupton MD, Klawans HL. Dream phenomena induced by chronic levodopa therapy. J Neural Transm 1978;43:143-151.

96. Borek LL, Kohn R, Friedman JH. Phenomenology of dreams in Parkinson's disease. Mov Disord 2007:22:198-202.

97. Kumar R. Approved and investigational uses of modafinil: an evidencebased review. Drugs 2008;68:1803-1839.

98. Hogl BE, Gomez-Arevalo G, Garcia S, et al. A clinical, pharmacologic, and polysomnographic study of sleep benefit in Parkinson's disease. Neurology 1998;50:1332-1339.

99. Guimaraes HC, Levy R, Teixeira AL, Beato RG, Caramelli P. Neurobiology of apathy in Alzheimer's disease. Arq Neuropsiquiatr 2008;66: 436-443.

100. Dujardin K, Sockeel P, Devos D, et al. Characteristics of apathy in Parkinson's disease. Mov Disord 2007;22:778-784.

101. Pedersen KF, Larsen JP, Alves G, Aarsland D. Prevalence and clinical correlates of apathy in Parkinson's disease: a community-based study. Parkinsonism Relat Disord 2009;15:259-299.

102. Schwartz JE, Jandorf L, Krupp LB. The measurement of fatigue: a new instrument. J Psychosom Res 1993;37:753-762.

103. Pluck GC, Brown RG. Apathy in Parkinson's disease. J Neurol Neurosurg Psychiatry 2002;73:636-642.

104. Hagell P, Brundin L. Towards an understanding of fatigue in Parkinson's disease. J Neurol Neurosurg Psychiatry 2009;80:489-492.

105. Chatterjee A, Fahn S. Methylphenidate treats apathy in Parkinson's disease. J Neuropsychiatry Clin Neurosci 2002;14:461-462.

106. Mendonca DA, Menezes K, Jog MS. Methylphenidate improves fatigue scores in Parkinson disease: a randomized controlled trial. Mov Disord 2007;22:2070-2076

107. Ferreri F, Agbokou C, Gauthier S. Recognition and management of neuropsychiatric complications in Parkinson's disease. CMAJ 2006;175:1545-1552

108. Aarsland D, Zaccai J, Brayne C. A systematic review of prevalence studies of dementia in Parkinson's disease. Mov Disord 2005;20: 1255-1263.

109. Caballol N, Marti MJ, Tolosa E. Cognitive dysfunction and dementia in Parkinson disease. Mov Disord 2007;22:S358-S366.

110. Williams-Gray CH, Foltynie T, Brayne CE, Robbins TW, Barker RA. Evolution of cognitive dysfunction in an incident Parkinson's disease cohort. Brain 2007;130:1787-1798.

111. Kummer A, Harsányi E, Dias FMV, Cardoso F, Caramelli P, Teixeira AL. Depression impairs executive functioning in Parkinson's disease patients with low educational level. Cogn Behav Neurol 2009; In press.

112. Dubois B, Burn D, Goetz C, et al. Diagnostic procedures for Parkinson's disease dementia: recommendations from the movement disorder society task force. Mov Disord 2007;22:2314-2324.

113. Poewe W, Wolters E, Emre M, et al. Long-term benefits of rivastigmine in dementia associated with Parkinson's disease: an active treatment extension study. Mov Disord 2006;21:456-461. 